\title{
Restorative Aesthetic Pleasures and the Restoration of Pleasure
}

\section{Ryan Paul Doran}

To cite this article: Ryan Paul Doran (2017) Restorative Aesthetic Pleasures and the Restoration of Pleasure, Australasian Philosophical Review, 1:1, 73-78

To link to this article: http://dx.doi.org/10.1080/24740500.2017.1296399

曲 Published online: 26 Mar 2017.

Submit your article to this journal ๘

山 Article views: 26

Q View related articles $₫$

View Crossmark data $\gtrsim$ 


\title{
Restorative Aesthetic Pleasures and the Restoration of Pleasure
}

\author{
Ryan Paul Doran \\ University of Sheffield and University of Antwerp
}

\begin{abstract}
I argue, contra Mohan Matthen, that at least some aesthetic pleasures arising from the appreciation of aesthetic features of artworks are what he calls 'r-pleasures' as opposed to 'f-pleasures' - and moreover, that the paradigm aesthetic pleasure (arising in response to beauty) appears to be an r-pleasure on Matthen's terms. I then argue that talk of $r$ - and f-pleasures does not distinguish different kinds, but two different features of pleasure; so this supposed distinction (at least) cannot be used to characterize a sui generis aesthetic pleasure.
\end{abstract}

ARTICLE HISTORY Received 1 August 2016; Revised 25 October 2016

KEYWORDS Aesthetic experience; beauty; pleasure; disinterestedness

\section{Introduction}

Mohan Matthen's account of aesthetic pleasure revives a tradition of attempting to characterize the aesthetic 'internally' - that is, by appealing to features of the experience had in response to aesthetic objects rather than to the properties of aesthetic objects themselves (see, for example, Beardsley [1982: 79] for this distinction). This welcome development has a venerable pedigree: Hume, Kant, Schopenhauer, Bell, and Beardsley all offer 'internal' accounts. But the internalist tradition has been in continual decline since the second half of the twentieth century, due in no small measure to influential objections from George Dickie [1964, 1965], and more recently Noël Carroll [2002]. While I think the internal tradition is the right one, I am not convinced that Matthen's account (or any other that posits a sui generis aesthetic state as some kind of pleasure) is looking in the right place.

In this article I apply critical pressure to Matthen's central distinction between $r$ pleasures (restoration or relief pleasures) and f-pleasures (facilitating pleasures), in order to resist his characterization of aesthetic pleasure as a species of the latter.

\section{R-pleasures as Aesthetic Pleasures}

According to Matthen, r-pleasures have two characteristic properties. First, they are experienced at the cessation of certain 'mental states,' which are 'departures from normal resting equilibrium' and 'physically and psychologically costly to prolong 
indefinitely' [7]. Second, arising out of that first property r-pleasures are 'passive' and 'retrospective,' and have 'no forward motivational force' [7]. So apart from providing an informative hedonic signal, r-pleasures are motivationally epiphenomenal.

Though not explicitly stated, it is implied in Matthen's account that satisfaction of a certain type of desire is necessary for $r$-pleasures to occur. To see why, let us first characterise a desire as a personal or subpersonal representation of some state of affairs, along with an attitude to its realization. Now, we can usefully divide desires into two broad types: (1) those for some prospective state of affairs not to occur, or for some present state of affairs to cease (call all of these 'non-obtainment desires'); and (2) those for some prospective state of affairs to be realized, or for some present state of affairs to continue (call these 'obtainment desires'). Satisfaction of either type gives rise to pleasure, but satisfaction of non-obtainment desires is apt to be experienced as a pleasant relief, so they are at least eligible to be r-pleasures. Satisfaction of obtainment desires, on the other hand, is not apt to result in relief (but rather in a joy or satisfaction), so they are not eligible to be r-pleasures.

Matthen's f-pleasures, unlike r-pleasures (but like urges or drives), 'motivate prospectively... . They motivate the continuation of the activity that gives rise to them' [8]. Appealing to a facilitating nexus or 'f-nexus'-a 'coordinated group of mental and bodily "preparations" that encourage, ease, and optimize [an activity]' [8]-he defines an f-pleasure as 'a conscious feeling that activates this f-nexus' [8]. ${ }^{1}$ Matthen claims that aesthetic pleasure is a species of f-pleasure.

While it is again not explicit in Matthen's account, the production of f-pleasures seems to involve an appraisal of the activity or object experienced in terms of desires or other self-representations. In thirsty drinking or hungry eating for example, the f-pleasure that activates the ' $\mathrm{f}$-nexus' is counterfactually dependent on having a desire.

With other f-pleasures, while a desire is not necessary they do involve (at least as a matter of fact) an appraisal of the activity in terms of representations of different aspects of the prior state of the organism (physically and psychologically) that determines whether pleasure will arise. Consider for example our pleasure in seeing a beautiful landscape. Looking at it does not satisfy any antecedent desire, but the landscape is pleasurable to behold so we are motivated to continue beholding it. Nonetheless, we only find this activity pleasurable, and only continue beholding it, so long as we are not bored or sated by it.

In light of these considerations, Matthen's proposed functional architecture of the pleasure system (at least in so far as it is constituted by r-and f-pleasures) is as shown in Figure 1.

Matthen's partial characterization of aesthetic pleasure as a species of f-pleasure, together with the fact that his characterization of $r$ - and $\mathrm{f}$-pleasure entails that no $\mathrm{r}$ pleasures can be f-pleasures, populates the categories of aesthetic and non-aesthetic pleasures in implausible ways. For some so-called r-pleasures are aesthetic pleasures.

Consider a musical example. Imagine listening to the first movement of Holst's The Planets-'Mars, The Bringer of War'. A rhythmically irregular ostinato provides the setting against which the melody repeatedly rises a fifth and drops a semitone, occasionally interrupted by dramatic bursts of sound. At the movement's sublime

\footnotetext{
${ }^{1}$ Matthen's notion of an f-pleasure seems very close to Csíkszentmihályi's notion of 'flow' [Csíkszentmihályi 1975].
} 


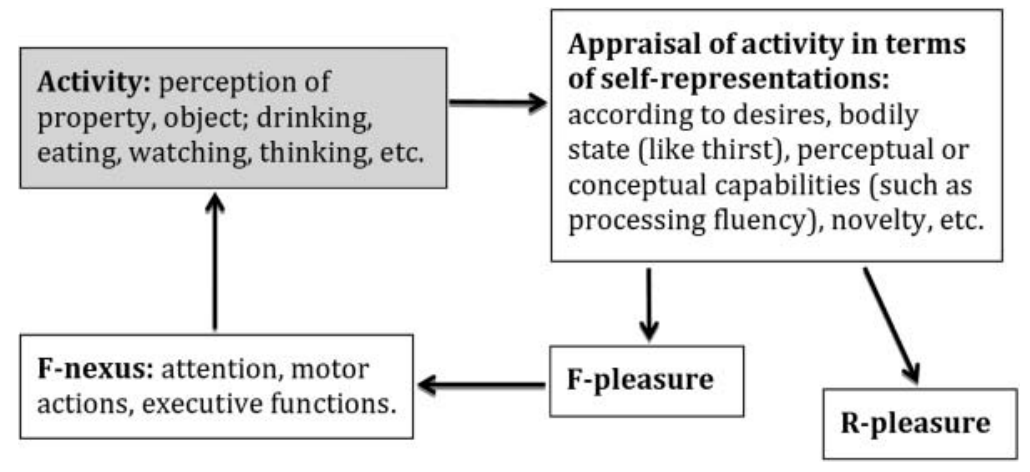

Figure 1. Functional architecture of the pleasure system, derived from Matthen.

dénouement the orchestra rises to a clattering climax, followed by a last violent and emphatic presentation of the rhythm that undergirds the movement. Armed with Matthen's framework, one might expect both $\mathrm{f}$ - and $\mathrm{r}$-pleasure when listening to 'Mars'. First, there is f-pleasure from anticipation of both local and final resolutions, underwritten by the rhythmic structure and melodic contour-and this pleasure impels us to continue engaging with the movement as it unfolds. Second, r-pleasure is occasioned in local resolutions of tension (the momentary crescendos of the militaristic bursts, the relative quiet moments afterwards, and the semitone drops after upward melodic leaps), and in the release at the end of the whole movement. These supposed $\mathrm{r}$ pleasures do not in themselves encourage continued engagement, but are rather the ends to which features generating anticipatory tension tend. Indeed, the movement's dénouement is exactly that-a wrapping up of the preceding elements; a final dissolution of tension rather than an invitation to continue listening [cf. Meyer 1956]. As rpleasures these cannot be aesthetic pleasures for Matthen [cf. Guyer this issue].

This, I submit, is an unpalatable outcome of Matthen's account. It is not clear why such r-pleasures should not count as aesthetic pleasures. After all, they arise out of sensitive attention to the formal and expressive features of 'Mars', just as the f-pleasures do. Indeed, the r-pleasures come from attending to parts of the same musical structure that gives rise to f-pleasures (i.e. those parts of the musical structure that resolve the pleasing anticipatory tension that has been built by earlier parts).

Supposing that they are indeed aesthetic pleasures, one might argue that these ostensible r-pleasures are in fact f-pleasures. The momentary resolutions of tension (by semitone drops, say) help to build further pleasurable anticipation, which makes us keep listening. Indeed, one might argue that the pleasure taken is only aesthetic to the extent that that is the case. But even if such resolutions do encourage continued listening, it is not obvious why the associated pleasures should only be aesthetic pleasures to the extent that they serve this facilitating role. Also, as this is certainly not the case at the movement's dénouement, on Matthen's account we are forced to conclude that any pleasure in that final resolution, at least, is disqualified as an aesthetic pleasure.

Setting aside this objection, there is another problem for Matthen's account. Pleasure taken in the contemplation of beauty, which is uncontrovertibly the paradigm aesthetic pleasure, seems to qualify as r-pleasure. Writing of art in general, but presumably referring more specifically and correctly to beautiful art, Matisse observes that it is 'a soothing, calming influence on the mind, something like a good armchair which 
provides relaxation from fatigue' [Matisse 1908: 42]. Similarly, Schopenhauer is surely right that the pleasure of beauty is brought on by a certain relief-the relief arising when beauty frees us from the suffering that otherwise accompanies our being driven to follow our own will, in all its inexhaustible vicissitudes. ${ }^{2}$ One need not buy into the loftier metaphysical fancies in which Schopenhauer casts his claim, to grasp its truth as a psychological thesis.

Advocates of Matthen's account might attempt to blunt the force of this objection that the pleasure taken in beauty qua beauty is both an aesthetic pleasure and an r-pleasure (in Matthen's terms), by flatly denying that these pleasures are genuinely r-pleasures. They could argue that pleasure taken in beauty does not come in the satisfaction of 'non-obtainment' desires, as required, but rather in the mere cessation of the pressure they exert. But this difference with Matthen's central cases of r-pleasures need not disable counterexamples of the sort I adduce above. One could listen to the beautiful second movement of The Planets-'Venus, The Bringer of Peace'-motivated by a pressing desire to alleviate one's worldly concerns by appreciating its beauty. Pleasure taken in the ensuing alleviation would indeed satisfy a 'non-obtainment' desire. And it is possible that once this is achieved there may be no wish to listen further. The pleasure experienced seems then to be one of Matthen's r-pleasures, and as a pleasure taken in the alleviation of one's worldly concerns through the perception of beauty it is, ipso facto, a pleasure taken in beauty qua beauty.

\section{Restoring the Unity of Pleasure}

A second, more wholesale objection, is that Matthen's distinction between $\mathrm{r}$ - and $\mathrm{f}$ pleasures does not amount to a metaphysically deep distinction between different 'kinds' of pleasure, nor between 'psychological structures' [6]. Rather, the distinction makes salient two different properties of just one psychological kind-pleasure simpliciter. Specifically, Matthen's notion of r-pleasures at most emphasizes the involvement of an appraisal in terms of self-representations in the production of pleasure; and his notion of f-pleasures can do no more than emphasize the necessity of motivation as an effect of pleasure. If this is so, at the very least Matthen cannot use this distinction to ground an account of what is unique in aesthetic pleasure.

I suggest, then, that Matthen's proposed architecture (see Figure 1) collapses into one involving just a single kind of pleasure (I call it the simple view; see Figure 2), and that this architecture can more elegantly accommodate the relevant cases.

According to the simple view, pleasure is a single unitary psychological kind that (1) has the causal power to motivate, for example, attention, executive functions, and motor actions; and (2) is sensitive to self-representations.

There are two reasons for preferring the simple view to Matthen's account. First, it is more parsimonious; it appears to do the same work with fewer ontological

\footnotetext{
2 For example, Schopenhauer claims that a beautiful view is a 'cathartic of the mind' [1966: 404]. More generally, Schopenhauer notes that 'whenever [beauty] presents itself to our gaze all at once, it almost always succeeds in snatching us, although only for a few moments, from subjectivity, from the thraldom of the will. ... The storm of passions, the pressure of desire and fear, the miseries of willing are then at once calmed and appeased in a marvellous way. For at the moment when, torn from the will, we have given ourselves up to pure, will-less knowing, we have stepped into another world, so to speak, where everything that moves our will, and thus violently agitates us, no longer exists' [1969: 197].
} 


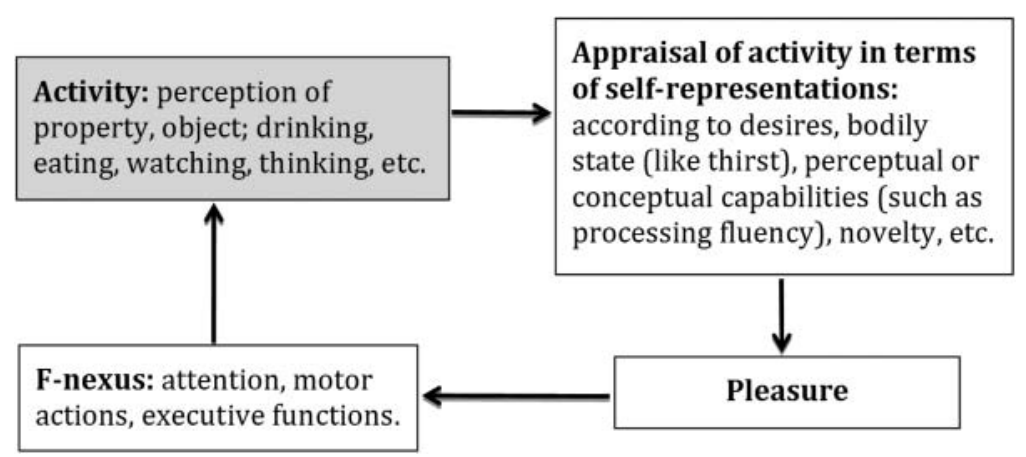

Figure 2. The simple view; a simplified functional architecture of the pleasure system, modified from Matthen's architecture (shown in Figure 1).

commitments. Second, and at least of equal importance, it seems to reflect more accurately the relevant phenomena.

How is this to be argued? Consider thirsty drinking. As we have seen, Matthen finds two pleasures here: one that occurs during the drinking, and motivates further drinking; and one that occurs immediately after, dissipates quickly, and does not motivate. But it is not necessary to posit these two kinds of pleasure. The supposed f-pleasure in this example seems rather to be an r-pleasure (to persist in using Matthen's terms).

First, the pleasure in thirsty drinking has at least one of the characteristic features of r-pleasures, since it results from satisfaction of a 'non-obtainment' desire. Not only is the supposed f-pleasure counterfactually dependent on a desire for hydration just as the supposed r-pleasure is: the f-pleasure diminishes as the desire is sated by the consumption of water, and to the extent that the water has properties apt for satisfying that desire (thirst-quenchingness, purity and coolness). Moreover, pleasure from drinking when thirsty has the phenomenology of a diminishing relief. If the pleasure were not taken in the satisfaction of the non-obtainment desire, it is hard to see why it should decrease as the desire diminishes and to the extent that the water has properties that are apt to satisfy the desire, and why it should feel like relief. So Matthen's appeal to a distinct kind of pleasure seems nugatory in this case.

Second, the supposedly distinct f-pleasure and r-pleasure both have causal efficacybut the attempted distinction obscures this fact. Pleasure during thirsty drinking certainly has an effect in facilitating further consumption; but the pleasure that comes once drinking has finished is still efficacious in the ' $\mathrm{f}$-nexus,' even if it does not cause continued drinking on that very occasion. As a result of this latter instance of pleasure, one is induced to attend better to the feeling of having had one's thirst quenched, and to the nature of the activity that quenched it. Moreover, one will be more likely to pursue the drinking of water in future, and discriminatively attend to and seek out cold and pure water when thirsty.

On Matthen's account then, we simply seem to be individuating pleasures in the wrong way in this case: the separately named manifestations are still instances of pleasure simpliciter, despite one coming before complete satisfaction of the relevant desire, and the other coming when satisfaction is achieved.

Even accepting this collapse of the original distinction between $r$ - and f-pleasures in cases like thirsty drinking, a defender of Matthen's account can still exploit two facts: at 
least some pleasures do not involve desire satisfaction; and r-pleasures seem to necessarily involve 'non-obtainment' desire satisfaction. Together, these facts might motivate a reworked distinction between f-pleasures and somewhat re-theorized r-pleasures (since r-pleasures have just been shown to motivate prospectively, in thirsty drinking).

Consider the example discussed earlier of the pleasure that comes in looking at a landscape experienced as beautiful. This activity need not satisfy any antecedent desire, but simply give rise to pleasure that motivates us to keep looking. This is quite plausible; and one might attempt a distinction on this basis, as do many proponents of 'disinterested pleasure'. But we could object that the f-pleasure here only motivates to the extent that it is constrained by an antecedent appraisal in terms of self-representations (such as the novelty of that landscape), just like our reformed r-pleasures.

Of course, this is not to deny that one can draw distinctions according to whether desires are involved (even 'obtainment' or 'non-obtainment' desires), or whether relief or satisfaction is felt, or whether the activity is of a certain kind. Certainly one can; and one is able to explain differences between different instances of pleasurable experience and episodes of activity in terms of these different components. But it is not established that any such distinction warrants acceptance of fundamentally different kinds of pleasure per se, or whether any such distinction can be used to ground some sui generis aesthetic state. Myself, I am not sanguine about any project to affirm these claims.

\section{Disclosure statement}

No potential conflict of interest was reported by the author.

\section{ORCID}

Ryan Paul Doran (iD http://orcid.org/0000-0003-3986-4693

\section{References}

Beardsley, Monroe C. 1982. Aesthetic Experience Regained, in The Aesthetic Point of View: Selected Essays, ed. M. Wreen and D. Callen, Ithaca: Cornell University Press: 77-92.

Carroll, Noël 2002. Aesthetic Experience Revisited, British Journal of Aesthetics 42/2: 145-168.

Csíkszentmihályi, Mihály 1975. Beyond Boredom and Anxiety: Experiencing Flow in Work and Play, San Francisco: Jossey-Bass.

Dickie, George 1964. The Myth of the Aesthetic Attitude, American Philosophical Quarterley 1/1: 56-65.

Dickie, George 1965. Beardsley's Phantom Aesthetic Experience. Journal of Philosophy, 62/5: 129-136.

Guyer, Paul, 2017. A Complex of Pleasures: Comment on 'The Pleasure of Art' by Mohan Matthen. Australasian Philosophical Review 1.1: 40-49.

Matthen, Mohan, 2017. The Pleasure of Art. Australasian Philosophical Review 1.1: 6-28.

Matisse, Henri 1908 (1995). Notes of a Painter, in Matisse on Art, ed. Jack D. Flam, Berkeley and Los Angeles: University of California Press: $30-43$.

Meyer, Leonard 1956. Emotion and Meaning in Music, Chicago: University of Chicago Press.

Schopenhauer, Arthur 1818 (1969). The World As Will and Representation, Volume I, trans. E.F.J. Payne, New York: Dover.

Schopenhauer, Arthur 1844 (1966). The World As Will and Representation, Volume II, trans. E.F.J. Payne, New York: Dover. 